
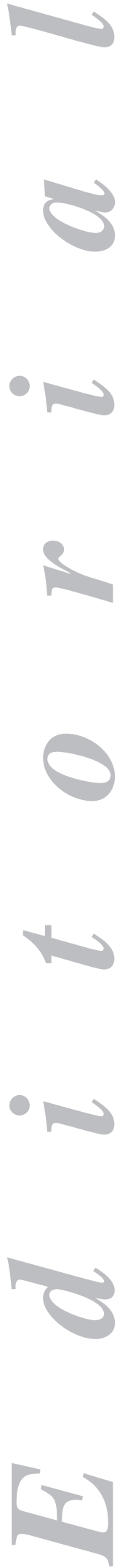

\section{Usefulness of anal ultrasonography in anal fistula}

Anal ultrasonography is a widely used technique for the diagnosis of morphologic changes in the anus and nearby structures of patients with anal incontinence, perineal sepsis, and anal tumors (1). From a technical viewstand, most work groups currently operate 7 - to $10-\mathrm{MHz}$ transducers allowing $360^{\circ}$, high-resolution images. The study is performed with no previous intestinal preparation and having the patient lye on his/her left side with both legs flexed $90^{\circ}$; except for rare instances, it requires no sedation or topic anesthesia. It lasts just a few minutes, may be performed anywhere (patient's room, examination room, operating room, etc.), and allows record storage in any format (electronic, paper) for further evaluation. The learning curve for benign anal conditions has not been studied thus far; however, it is deemed to be short when ultrasonography is performed by professionals with experience in the ano-rectal region. To validate their results, some authors document at least 100 examinations (2). While this is an observer-dependent test, intra- and inter-observer variability has been shown to be acceptable -with a higher concordance in the former case- regarding the measurement and identification of anal sphincter rupture (3). Many studies have assessed the ultrasonographic anatomic patterns of the anal canal in healthy volunteers (4-7), and demonstrated this technique's reproducibility $(6,7)$.

In normal subjects conventional anal ultrasonography is very useful to identify those basic structures in the anal canal that will serve as reference items in classifying and establishing the complexity of fistulas, the hypoechoic internal anal sphincter (IAS), the hyperechoic external anal sphincter (EAS), and proximally the puborectal muscle, which exhibits the same ultrasonographic characteristics of EAS, and forms an anteriorly-open U-shaped loop embracing the rectum. Under normal conditions identifying and measuring these structures is usually an easy task. However, when traumatic, septic or fibrotic alterations are concurrently present tissues change their ultrasound refringence and render the process much more difficult. Similarly, a lesion's extent or height may on occasion result in technical difficulties regarding assessment.

The most widely used anal fistula classification is that by Parks (8), who divided fistulas according to their anatomic relation to anal sphincters into interspincteric, transsphincteric, suprasphincteric, and extrasphincteric types. Secondary routes (extensions of the primary traject) may turn to the intersphincteric plane, ischiorectal fossa, postanal space, and supraelevator space. Furthermore, in the case of transsphincteric fistulas the theoretical EAS portion including the primary traject separates "higher" from "lower" lesions. By using these classification descriptive guidelines a good topographic relationship is established between the fistula and involved muscles, which will allow a preview of functional damage as induced by fis- 
tulotomy with curative intent on anal sphincter muscles. The usefulness of anal ultrasonography to establish Parks' types has been fully consolidated. In contrast, the usefulness of this method to tell "higher" from "lower" fistulas is not so much documented, as the image obtained in the axial plane makes it occasionally difficult to accurately establish the level at which the fistula crosses the EAS. In clinical practice this subdivision will predict surgical technical difficulties, as well as risks for anal incontinence.

In addition, complex fistulas include a wide range of possibilities (high fistulas, previous muscular lesions, anterior transsphincteric fistulas in women, external orifices and multiple routes, cavities, horse-shoe fistulas, etc.) requiring a complex surgical technique, and represent the highest percentage of sphincteric dysfunctions and relapses. In this sense a recent study by Sygut et al. (9) in 300 patients having undergone ultrasonography both before and after surgery, and who were at least monitored for one year, has seen $0 \%$ incontinence and $7.4 \%$ relapses in patients with lower fistula, whereas the range of incontinence (13.3 to $40 \%$ ) and relapses (16.8 to $40 \%$ ) in complex fistulas was significantly higher and depended on subtype (increases in extrasphincteric lesions and in those with multiple trajects).

The goals of anal fistula management and treatment were accurately established by Finlay (10): identifying fistula anatomy, draining any collections, eradicating fistula trajects, preventing recurrence, and preserving continence and sphincteric integrity. This latter point is transcendental, as up to $52 \%$ of patients undergoing fistulectomy may develop some incontinence, which is mild in most cases $(11,12)$.

Basically, surgeons must strive to cure with no sequels, and thus should try their best not to section or damage sphincters. As this is virtually impossible nowadays, surgeons must have a maximum of morphologic data available so that surgical technique (fistulectomy, fistulectomy with placement of seton, mucosal advance techniques, etc.) may be individualized, and several surgical stages may even be planned for complex cases.

What one should ideally demand from a technique regarding anatomic identification is the capability to demonstrate the external orifice(s), internal orifice, primary traject and secondary routes, and presence and extension of cavities, and also to assess sphincter integrity and even functional capacity. Currently instrument-driven physical exploration with or without anesthesia, ultrasonography, and magnetic resonance imaging (MRI) are also available.

The significance that anal ultrasonography has had in the topographic study of anal fistula has been and still is controversial. Early prospective studies that analyzed the diagnostic capabilities of anal ultrasonography (13) taking the physical examination of the anal canal under anesthesia (surgical exploration) as a reference demonstrated that ultrasounds has the same diagnostic yield as preoperative physical examination (regardless of the exploring surgeon's experience) for intersphincteric and transsphincteric fistulas, but a poor capability to identify the internal orifice, suprasphincteric and extrasphincteric fistulas, and presence of secondary routes.

The use of echogenicity-enhancing agents (hydrogen peroxide mainly) injected through the external orifice has considerably increased the diagnostic utility of anal ultrasonography $(2,14-20)$. Diluted hydrogen peroxide (3-5\%) is easily accessible, cheap, easy to use, and safe, and its use has thus gradually increased. Differences regarding the diagnostic accuracy of this technique as reported in the literature mainly result from differences in the criteria used for reference pattern (surgical findings or preoperative physical examination), the ultrasonographic diagnostic criteria re- 
quirable to define a fistula or its internal orifice, technical variation in the use of contrast agents, research team experience, and recording system quality. Regarding finger exploration or the use of standard ultrasounds, peroxide administration increases the diagnostic capability of ultrasonography in anal fistula by 58 and 33\%, respectively (16). Using hydrogen peroxide and taking surgical result as a reference, the success rate in the detection of fistula trajects is $85-95 \%(2,15,19,20)$, in the detection of internal orifices is 48 to $94.7 \%(2,15,19-21)$, and in the classification of fistulas is 77 to $95 \%(2,19-21)$.

A major problem of lesion identification using both physical and ultrasonographic exploration is structural changes of relapsing complex fistulas. The presence of fibrosis, scarring, sphincter lesions, and multiple cavities modifies echogenicity and topographic anatomy, and thus makes it much more difficult to identify minimal structures warranting a surgical strategy. In this issue of our journal, Fernandez-Frías et al. (22) prospectively discuss the diagnostic capabilities of hydrogen peroxide-enhanced anal ultrasonography in patients with relapsing complex anal fistula versus non-operated complex anal fistula. These authors, using a sectorial $\left(180^{\circ}\right)$ echograph and high-concentration (50\%) hydrogen peroxide, demonstrate that anal ultrasonography is significantly superior to preoperative physical examination in non-operated complex fistulas regarding more accurate classifications (94.7 vs. 78.9\%), internal orifice localization, and particularly residual cavity detection (84 vs. 16\%). However, in relapsing complex fistulas no statistically significant differences are reached for traject classification (93.8\% ultrasounds vs. $81.3 \%$ physical exploration) or internal orifice detection, but differences remain in the detection of residual cavities (69vs. 31\%). No differences are seen in the diagnostic capabilities of hydrogen peroxide-enhanced ultrasonography for any of the analyzed parameters between both fistula types (non-operated vs. relapsing). The results obtained by these authors regarding diagnostic certitude are comparable to those in the best series reported, even if they use a sectorial $180^{\circ}$ echograph instead of a $360^{\circ}$ echograph as used by most authors, which suggests that ultrasonography has the same diagnostic yield for relapsing fistula.

Computerized 3D reconstruction of bidimensional ultrasonograms is currently used to improve diagnostic yield. Early results in patients with non-relapsing cryptoglandular fistula (23) reveal that 3D images obtained following hydrogen peroxide enhancement offer a diagnostic certitude of $94.1 \%$ for primary trajects, $91.2 \%$ for internal orifice identification, $96.1 \%$ for secondary trajects, $100 \%$ for abscesses, and $96.1 \%$ for horse-shoe fistulas.

Anal endosonography for chronic inflammatory bowel disease, primarily Crohn's disease, has been used for several years now not only in the identification of lesion type and the establishment of surgical criteria, but also as an objective procedure for medical therapy assessment (antibiotics, immunosuppressants, infliximab, etc.). It is important to highlight the significance of avoiding aggressive surgery as much as possible for inflammatory perianal disease, given its high relapse and recurrence rates. On the other hand, it is essential that no errors are made in the detection or image interpretation of lesions (collections) requiring drainage. Recourse to seton and Petzer drainage placement for prolonged periods is increasingly common in this condition, and careful fistulectomy regarding extension is occasionally used combined with medical therapies attempting to improve quality of life and prevent relapse/recurrence. In perianal Crohn's disease imaging techniques have an excellent diagnostic yield. Studies in the Mayo Clinic (24) have shown that the diagnostic capability of ultrasonography alone is $91 \%$, with this measurement being $87 \%$ 
for magnetic resonance imaging, and $91 \%$ for physical exploration under anesthesia; however, diagnostic certitude is $100 \%$ when two of these three methods are combined. Ultrasonographic studies have demonstrated that high recurrence rates in fistulizing disease following treatment with infliximab (25), or with infliximab in combination with ciprofloxacin (26), are due to the fact that trajects persist as seen with ultrasounds, while the external orifice is apparently closed on visual inspection. These findings support the notion of a highly individualized monitoring of patients using imaging techniques (ultrasonography or magnetic resonance imaging), as the disappearance of morphologic signs detected with these techniques will point at greater therapeutic efficacy and smaller relapsing potential.

The rationale for using imaging techniques in patients with anal fistula must be based on their implications regarding a higher diagnostic yield versus physical examination with anesthesia, as this will entail an independent influence on management (primarily on the surgical strategy), and the refinement of potential prediction regarding postsurgical risk for complications (relapse, incontinence), information that must be reported to patients.

While many work teams insist that a better topographic knowledge of fistulas (primarily complex fistulas) during the preoperative period by using anal endosonography decreases the number of both relapses and undesirable effects (anal incontinence), few data demonstrate such statements. Some MRI studies suggest that MR images predict postoperative complications better than a physical examination with anesthesia (27), have led to changes in surgical technique by surgeons seeing them in the operating room (24\% of relapsing anal fistulas) (28), and have decreased the number of complications (relapses) by up to $75 \%$ in complex fistulas (29). Using anal ultrasonography, the disclosure of an ultrasonographic report in the operating room when a diagnostic strategy had already been decided has led surgeons to change their surgical approach in $44 \%$ of patients with anal fistula (30), and surgical strategies based on hydrogen peroxide-enhanced 3D ultrasonography for patients with non-relapsing cryptoglandular anal fistula allowed an excellent outcome for 102 patients (98\% cured, 2\% relapsed, 0\% incontinence) (23). This work had no control group, and therefore we cannot know whether results would have been similar if only physical exploration-derived data had been used in the operating theater; thus better designed studies are required to accurately, independently assess the extent of diagnostic improvement with this technique as compared to instrument-based physical exploration by expert surgeons within the operating room. What does seem likely is that combining information from imaging studies with data derived from physical examination under anesthesia will considerably facilitate decision making.

Since ultrasonography has a diagnostic capability similar to MRI, we deem the former the technique of choice when costs and availability are considered, with MRI being used when judged crucial.

In summary, from a practical point of view, and considering the significance that the best possible knowledge on the topographic characteristics of anal fistula has for surgeons, we may conclude that anal ultrasonography is unnecessary for most lower cryptoglandular fistulas, where physical exploration may perfectly delimit trajects and internal orifices. In contrast, for complex fistula, relapsing fistula, patients with inflammatory bowel disease, and surgeons entertaining the least doubt on the presence of occult sphincteric lesions (obstetric, traumatic, etc.) anal endosonography is always advisable before surgery. However, some authors, driven by medico-legal implications (defensive medicine) systematically perform preoperative or intraoper- 
ative sonograms for all sorts of fistulas (31). We believe that such behavior results in excessive demand for resources, and on occasion may promote careless medical practice (ordering an echogram and not examining the patient appropriately). Among imaging techniques for the study of anal conditions ultrasonography is a very useful method that should become rapidly integrated by multidisciplinary teams managing this disease.

\author{
M. Mínguez Pérez and E. García-Granero \\ Services of Gastroenterology and ' Coloproctology. \\ Hospital Clínico Universitario. Valencia, Spain
}

\title{
REFERENCES
}

1. Felt-Bersma RJ, Cazimer M. Endosonography in anorectal disease: an overview. Scand J Gastroenterol 2006; 243 (Supl.): 165-74

2. Ortiz H, Marzo J, Armendáriz P, Jiménez G. Valor de la ecografía anal con inyección de agua oxigenada en el diagnóstico de fístulas perianales. Cir Esp 2002; 6: 315-7.

3. Gold DM; Halligan DS, Kmiot WA, Bartram CI. Intraobserver and interobserver agreement in anal endosonography. Br J Surg 1999; 86: 371-5.

4. Law PL, Bartram CI. Anal endosonography: technique and normal anatomy. Gastrointest Radiol 1989; 14: 349-53.

5. Eckardt VF, Jung B, Fischer B, Lierse W. Anal endosonography in healthy subjects and patients with idiopathic fecal incontinence. Dis Colon Rectum 1994; 37: 235-42.

6. Nielsen MB, Hauge C, Rasmussen OO, Pedersen JF, Christiansen J. Anal sphincter size masured by endosonoggraphy in healthy valunteers. Effect of age, sex and parity. Acta Radiol 1992; 33: 453-6.

7. Poen AC, Felt-Biersma RJF, Cuesta MA. Normal values and reproducibility of anal endosonographic measurements. Eur J Ultrasound 1997; 6: 103-10.

8. Parks AG, Gordon PH, Hardcastle JD. A classification of fistula-in-ano. Br J Surg 1976; 63: 1-12.

9. Sygut A, Zajdel R, Kedzia-Budziewska R, Trzcinski R, Dziki A. Late results of treatment of anal fistulas. Colorectal Disease 2006 (in press, electronic version).

10. Finlay IG. Objetives in managemente. In: Phillips, RK, Lunniss PJ, editors. Anal fistula. London: Chapman \& Hall; 1996. p. 78-80.

11. García Aguilar J, Belmonte C, Wong WD, Goldberg SM, Madoff RD. Anal fistula surgery. Factors associated with recurrence and incontinence. Dis Colon Rectum 1996; 39: 723-9.

12. Lunniss PJ, Kamm MA, Phillips RKS. Factors affecting continence after surgery for anal fistula. Br J Surg 1994; 81: 1382-5.

13. Choen S, Burnett S, Bartram Ci, Nicholls RJ. Comparison between anal endosonography and digital examination in the evaluation of anal fistulae. Br J Surg 1991: 78; 445-7.

14. Cheong DM, Nogueras JJ, Wexner SD, Jagelman DG. Anal endosonography for recurrent anal fistulas: image enhancement with hydrogen peroxide. Dis Colon Rectum 1993; 36: 1158-60.

15. Poen AC, Felt-Bersma RJ, Eijsbouts QA, Cuesta MA, Meuwissen SG. Hydrogen peroxide enhanced transanal ultrasound in the assessment of fistula-in-ano. Dis Colon Rectum 1998; 41: 1147-52.

16. Cho DY. Endosonographic criteria for an internal opening of fistula-in-ano. Dis Colon Rectum 1999; 42: 5158.

17. Kruskal JB, Kane RA, Morrin MM. Peroxide enhanced anal endosonography: thecnique image interpretation, and clinical applications.Radiographics 2001; 21: S173-89.

18. Sloots CE, Felt-Bersma RJ, Poen AC, Cuesta MA. Assessment and classification of never operated and recurrent cryptoglandular fistulas-in-ano using hydrogen peroxide enhanced transanal ultrasound. Colorectal Disease 2001; 3: 422-6.

19. Lengyel AJ, Hurst NG, Williams JG. Pre-operative assessement of anal fistulas using endoanal ultrasound. Colorectal Diseases 2002; 4: 436-40.

20. Navarro-Luna A, García-Domingo MI, Rius-Macías J, Marco-Molina C. Ultrasound study of anal fistulas with hydrogen peroxide enhancement. Dis Colon Rectum 2004; 47: 108-14.

21. Ratto C, Gentile E, Merico M, Spinazzola C, Mangini G, Sofo L, et al. How can the assessment of fistula in ano be improved? Dis Colon Rectum 2000; 43: 1375-82.

22. Férnandez-Frías AM, Pérez-Vicente F, Arroyo A, Sánchez Romero AM, Navarro JM, Serrano P, et al. ¿Es útil la ecografía endoanal en el estudio de la fístula anal compleja recidivada? Rev Esp Enferm Dig 2006; 98 (8): 573-81.

23. Ratto C, Grillo E, Parello A, Costamagna G, Doglietto GB. Endoanal ultrasound-guided surgery for anal fistula. Endoscopy 2005; 37: 722-8.

24. Schwarz DA, Wiersma MJ, Dudiak KM, Fletcher JG, Clain JE, Tremaine WJ, et al. A comparison of endo- 
scopic ultrasound, magnetic resonance imaging, and exam under anesthesia for evaluation of Crohn's perianal fistulas. Gastroenterology 2001; 121: 1064-72.

25. Ardizzone S, Maconi G, Colombo E, Manzionna G, Bollani S, Bianchi Poro G. Perineal fistulae following infliximab treatment: clinical and endosonographic outcome. Inflamm Bowel Dis 2004; 10: 91-6.

26. West RL, Van Der Woude Cj, Hansen BE, Felt-Bersma RJ, Van Tilbrg AJ, Drapers JA, et al. Clinical and endosonographic effect of ciprofloxacin on the treatment of perianal fistulae in Crohn's disease with infliximab: a double-blind placebo-controlled study. Aliment Pharmacol Ther 2004; 20: 1329-36.

27. Chapple KS, Spencer JA, Windsor AC, Wilson D, Ward J, Ambrose NS. Prognostic value of magnetic resonance imaging in the management of fistula-in-ano. Dis Colon Rectum 2000; 43 (4): 511-6.

28. Beets-Tan RG, Beets GL, van der Hoop AG, Kessels AG, Vliegen RF, Baeten CG, et al. Preoperative MR imaging of anal fistulas: Does it really help the surgeon? Radiology 2001; 218(1): 75-84.

29. Buchanan G, Halligan S, Williams A, Cohen CR, Tarroni D, Phillips RK, et al. Effects of MRI on clinical outcome of recurrent fistula-in-ano. Lancet 2002; 360 (9346): 1661-2.

30. Tilney HS, Heriot AG, Trickett JP, Edwars Dp, Mellor SG, Gudgeon AM. The use of intra-operative endoanal ultrasound in perianal disease. Colorectal Disease 2006; 8: 338-41.

31. Richard M. Anal abscesses and fistulas. ANZ J Surg 2005; 75: 64-72. 